\title{
Fabrication and mechanical properties of self-reinforced poly(ethylene terephthalate) composites
}

\author{
J. C. Chen ${ }^{1}$, C. M. Wu ${ }^{2 *}$, F. C. Pu ${ }^{2}$, C. H. Chiu ${ }^{2}$ \\ ${ }^{1}$ Graduate Institute of Materials Science and Technology, Vanung University, Chungli, Taiwan, ROC \\ ${ }^{2}$ Department of Fiber and Composite Materials, Feng-Chia University, 100, Wenhwa Rd., Taichung, Taiwan 40724, ROC
}

\begin{abstract}
Self-reinforced poly(ethylene terephthalate) (PET) composites prepared by using a modified film-stacking technique were examined in this study. The starting materials included a high tenacity PET yarn (reinforcement) and a low melting temperature biodegradable polyester resin (matrix), both of which differ in their melting temperatures with a value of $56^{\circ} \mathrm{C}$. This experiment produced composite sheets at three consolidation temperatures $\left(T_{\mathrm{c}}: 215,225\right.$, and $\left.235^{\circ} \mathrm{C}\right)$ at a constant holding time $\left(t_{\mathrm{h}}: 6.5 \mathrm{~min}\right)$, and three holding times $(3,6.5$ and $10 \mathrm{~min})$ at a constant consolidation temperature of $225^{\circ} \mathrm{C}$. This study observed a significant improvement in the mechanical properties obtained in self-reinforced PET composites compared to the pure polyester resin. The results of tensile, flexural, and Izod impact tests proved that optimal conditions are low consolidation temperature and short holding time. The absorbed impact energy of the best self-reinforced PET composite material was $854.0 \mathrm{~J} / \mathrm{m}$, which is 63 times that of pure polyester resin.
\end{abstract}

Keywords: mechanical properties, processing technologies, poly(ethylene terephthalate) (PET), self-reinforced PET composites, film-stacking

\section{Introduction}

The negative environmental impact of the steadily increasing use of plastic and composite materials requires the development of new combinations of materials, possibly with improved properties, but with reduced environmental harm. Consequently, the development of recycling-friendly thermoplastic composites has become a top priority. In fact, there is a growing interest to either improve the methods for recycling and reusing existing composites, or develop new and intrinsically more suitable composites. Creating all-polymeric material, especially self-reinforced polymeric composite material is an excellent alternative to traditional fiber-reinforced composites because both the reinforcing and the continuous phases involve polymers belonging to the same family of polymers [1-3]. These poly-

\footnotetext{
${ }^{*}$ Corresponding author, e-mail: cmwu@fcu.edu.tw

(c) BME-PT
}

mers can be entirely melted down at the end of their product life for recycling.

The self-reinforced polymeric composite material possesses many advantages and features, such as thermoformability, high stiffness, high tensile strength, outstanding impact resistance at low density, and containing no glass [2-5]. Because the reinforcement and the matrix are compatible chemically; therefore, they usually have no interfacial problems. Fiber manufactured from a highly oriented form of the same polymer matrix provides adequate reinforcing strength, resulting in a selfreinforced polymeric composite material with improved specific stiffness and specific strength, especially from the aspect of dynamic toughness and elongation at break. Additionally, the waste/ scrap materials can be recycled by melting which satisfies the demand for green material. 
In 1975, Capiati and Porter [6] initially developed a polyethylene/polyethylene composite and introduced the concept of self-reinforced polymeric composites. Ward and coworkers [7-11] further developed this type of composite material using the 'hot compaction' technique. Following this study, opening literatures has reported numerous studies on the preparation of self-reinforced polypropylene (PP) $[8,11-17]$, polyethylene terephthalate (PET) [4, 9, 18-19], polymethyl methacrylate [20], liquid crystal copolymer [21-22], polylactic acid [23], and polyamide [24-26] composites. In particular, the self-reinforced PP composites are now available on the market under the trade name $\operatorname{Curv}^{\circledR}$, Armordon $^{\circledR}$, and Pure ${ }^{\circledR}$ [5]. Numerous products, such as automotive components, luggage, sporting goods and protective materials already apply self-reinforced PP composites.

The main challenge when producing a self-reinforced polymeric composite material is combining the fiber and matrix into one composite. Various fabrication methods such as hot compaction, overheating, co-extrusion, film stacking, and traditional melting or powder impregnation can produce the self-reinforced composite materials [2-3]. In most cases, the hot compaction process produces the self-reinforced polymeric composites; however, now $\mathrm{Curv}^{\circledR}$ uses it for production. This process occurs via the partial melting of the fibers so that the molten outer surface of the fibers becomes the matrix after cooling. However, the processing window of hot compaction is small, typically about $5^{\circ} \mathrm{C}$ or below between the feasible consolidation temperature and the melting temperature of the fiber. In 2006, Alcock et al. [17] improved the hot compaction process using a combination of constraining and co-extrusion. The processing window for creating these self-reinforced PP composites can be enlarged to approximately $20-40^{\circ} \mathrm{C}$ creating excellent bonding between the co-extruded two types of PP tapes of different melting temperatures. Presently manufacturers fabricate Armordon ${ }^{\circledR}$ and Pure ${ }^{\circledR}$ by applying the co-extrusion technique.

Many studies have explored the film stacking method for manufacturing self-reinforced polymeric composites [15-16, 27-29]. After producing the reinforced textile structure, it is sandwiched between films, which should overtake the role of the matrix after melting and subsequent cooling.
Therefore, the reinforcing and matrix-forming polymer layers and films alternately lie on each other before producing the hot pressed consolidated composites. The advantages of the film stacking method include a wide processing window, freedom of material selection, and no expensive pre-production. The film stacking self-reinforced PP composites were the first to utilize the textile reinforcing structure [30-31].

The major problem with the aforementioned methods above for manufacturing self-reinforced polymeric composite material is damaging the reinforcement, while melting the matrix polymer during the forming process. Excessive heating results in fiber relaxation and ultimately causes the fiber to lose molecular orientation, whereas, insufficient heating leads to a poor interfacial bonding between the fiber and the matrix. Some studies successfully used a small temperature-processing window to prepare self-reinforced polymeric composites but reduce the versatility of the processing route. Therefore, materials, that maximize the difference in melting temperatures between the matrix and reinforcement polymers, are vital for forming the material, while ensuring that the reinforcement fibers remain unaffected by the consolidation temperature. Using fibers produced from the same material, but with different drawing ratios, can enlarge the processing window. Bárány, Karger-Kocsis and coworkers [14-16, 32] reported another novel approach that used the film stacking method to prepare the self-reinforced PP composites by taking the polymorphism-related difference in the melting range between the $\beta$ and $\alpha$ phases PP. Bárány and Karger-Kocsis could enlarge the processing window for creating these self-reinforced PP composites to $25^{\circ} \mathrm{C}$. Alcock etc. [33] increased the size of the processing window of self-reinforced PP composites to $40^{\circ} \mathrm{C}$ by exploiting the random copolymer with a lower melting temperature. All of the previously mentioned efforts have contributed to the commercialization of self-reinforced PP composites. However, PP has relatively low mechanical properties, particularly at elevated temperatures. The potential applications of self-reinforced PP composite materials are currently limited; therefore, exploring combinations of new materials and extending the processing window is critical. 
In 2004, Hine and Ward researched the hot compaction technique with woven poly(ethylene terephthlate) (PET) multifilaments [9]. The results showed that hydrolytic degradation occurred rapidly at the temperatures required for successful compaction. This led to the embrittlement of the resulting materials and increased the holding time. In 2005, Rojanapitayakorn et al. [18] studied the effect of various hot compaction temperatures on crystallinity, molecular orientation, and mechanical properties of self-reinforced PET (srPET) composites. Yao et al. [19] prepared srPET composites by compressing molding laminations of thin amorphous PET films and high crystallinity PET fabrics. The results revealed that an increase in the holding time creating a reduced interfacial adhesion and mechanical properties of srPET composites because the sample becomes brittle. The authors believed that thermal and hydrolytic degradation cause the embrittlement. Therefore, in order to minimize the degradation, the hot compaction process should be performed as rapidly as possible.

Bárány, Karger-Kocsis and coworkers [14-16, 34] studied the processing parameters of self-reinforced PP composites and concluded that the consolidation temperature is more suited to control the parameter than the holding time when the consolidation pressure is invariable. The increase in the consolidation temperature caused an increase in tensile properties, but a decrease in the impact energy. An increase in the holding time did not cause any large changes in the tensile properties, whereas the impact energy slightly improved. However, Alcock et al. [12] reported that the unidirectional self-reinforced PP composites prepared by co-extruded technique showed little deviation in the mechanical properties from temperature consolidation. Khondker et al. [25] studied the mechanical properties of aramid/ nylon plain knitted composites fabricated by varying the holding time. They found that the tensile strength of the reinforcing aramid fiber decreased significantly with an increasing duration of heat exposure, whereas the tensile modulus of aramid fiber was insensitive to the length of heat exposure. Therefore, tensile modulus and strength of aramid/ nylon composites increase and decrease, respectively, with a longer holding time. It is evident that the mechanical properties of self-reinforced polymeric composite materials are sensitive to both con- solidation temperature and holding time, depending on the characters of the constituting materials and fabrication method.

Based on the aforementioned introduction, this study is aware of the fact that the exploration of new materials combinations and ascertaining the optimal processing conditions are most critical for self-reinforced polymeric composite materials. Poly(ethylene terephthalate) (PET), a commercially available oriented polymer, has the potential to show more favorable mechanical and temperature performance than the PP fiber or tape. However, studies of srPET composite materials are limited. Therefore, in this study, biodegradable polyester was uses as matrix material and woven fabric of PET oriented homopolymer was used as reinforcement for developing srPET composite materials. The optimal processing conditions such as consolidation temperature and holding time, for this srPET composite material were investigated.

\section{Experimental}

\subsection{Materials}

In this study, biodegradable polyester $\left(\right.$ Apexa $^{\circledR}$ 4024, Dupont, Japan) in the form of pellets, were used as the matrix. The measured melting point of the biodegradable polyester determined by DSC is $198^{\circ} \mathrm{C}$ (Figure 1). The recommended processing temperature in the guideline of the biodegradable polyester resin is approximately $215^{\circ} \mathrm{C}$. The viscosity was studied by capillary rheometry (Rheo-tester 1501, Göttfert, Germany) to understand the flow and impregnation behaviors of the matrix. Figure 2 displays the viscosity behaviors of the polyester

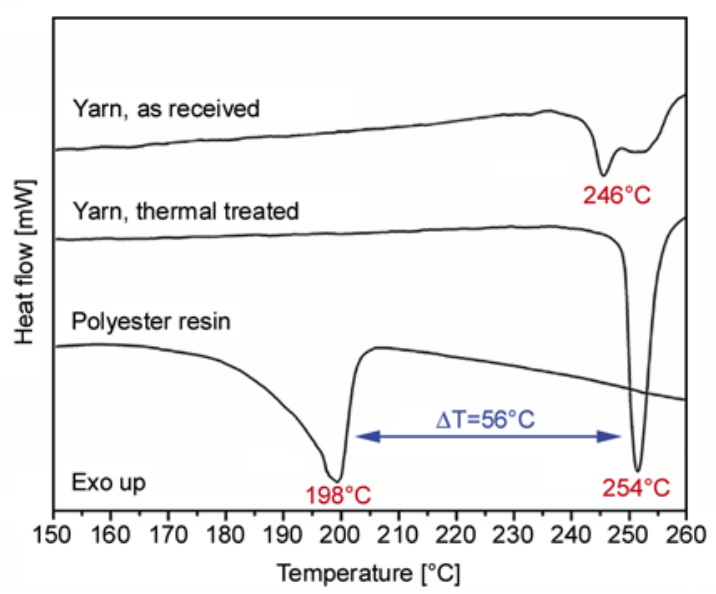

Figure 1. Thermograms of the polyester resin and the reinforcing PET yarn before and after thermal treated 


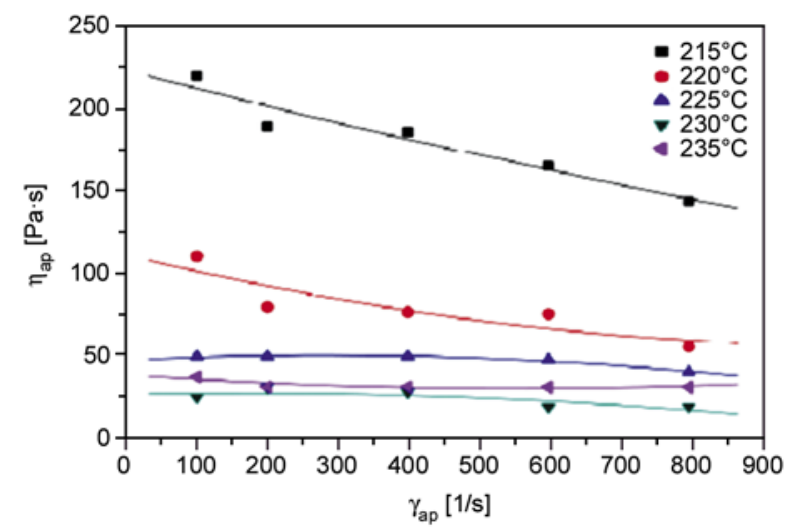

Figure 2. The viscosity behaviors of the polyester resin at testing temperatures of 215 to $235^{\circ} \mathrm{C}$ determined by capillary rheometry under various shear rates

resin at testing temperature of 215 to $235^{\circ} \mathrm{C}$. The average viscosities measured at 215,225 and $235^{\circ} \mathrm{C}$ are 180, 46 and $31 \mathrm{~Pa} \cdot \mathrm{s}$. Such high viscosity in the polyester resin is about two orders higher than that of a conventional thermoset resin. The conventional thermosetting processing methods are thus not utilized for the polyester resin and some others must be developed.

This study used a PET plain-woven construction fabric as reinforcement. The PET yarn for high denier industrial (HDI) purpose (grade: dope dyed color yarn) was provided by Far Eastern New Century Corporation, Taiwan (www.fenc.com), consisting of 2000 denier multifilament bundles with tenacity of $7.8 \pm 0.3 \mathrm{~g} /$ denier and elongation of $14 \pm 2 \%$. Every multifilament bundle consists of 182 filaments with filament diameter of $32 \mu \mathrm{m}$. The multifilament bundles were dope-dyed in black to imitate the appearance of carbon fabric. The PET plainwoven fabric has a fabric weight of $280 \mathrm{~g} / \mathrm{m}^{2}$. The warp and weft direction of the fabric ( 5 bundles $/ \mathrm{cm}$ ) balance reasonably well. Double melting points were obtained for the as received PET plain-woven fabric with initial melting at $246^{\circ} \mathrm{C}$ (Figure 1).

\subsection{Sample preparation}

This study presents a modified film stacking technique to produce high quality impregnated and void free srPET composites. To prevent PET fiber shrinkage and relaxation during the heat consolidating processing, the fabric was first subjected to a thermal setting for $30 \mathrm{~min}$ at $230^{\circ} \mathrm{C}$. As shown in Figure 1, the single and sharp melting point for the thermal treated PET plain-woven fabric was obtained at $254^{\circ} \mathrm{C}$. A melting temperature difference between reinforcing fiber and matrix was $56^{\circ} \mathrm{C}$. At first, the matrix was prepared into a thin film form (thickness of $400 \mu \mathrm{m}$ ) using compression molding at $200^{\circ} \mathrm{C}$ for $3 \mathrm{~min}$, at a pressure of $5 \mathrm{MPa}$. This was followed by quenching the matrix in water by covering it with Teflon films. The srPET composite lamina with average thickness of $\sim 480 \mu \mathrm{m}$ was prepared using the procedure: laid-up one layer of thermal treated PET fabric on PET thin film at $200^{\circ} \mathrm{C}$ for $1 \mathrm{~min}$ under a pressure of $5 \mathrm{MPa}$ followed by quenching in water with the covering of Teflon films. The srPET laminates were prepared by stacking five layers of lamina at various $T_{\mathrm{c}}$ and holding times at a pressure of $10 \mathrm{MPa}$ followed by slow cooling to room temperature and demolded. Three consolidation temperatures $\left(T_{\mathrm{c}}: 215,225\right.$, and $\left.235^{\circ} \mathrm{C}\right)$ with constant holding time $\left(t_{\mathrm{h}}: 6.5 \mathrm{~min}\right)$ and three holding times $(3,6.5$ and $10 \mathrm{~min})$ at constant consolidation temperature: $225^{\circ} \mathrm{C}$ were selected to determine the optimal processing conditions. Figure 3 shows a typical cross-section of the srPET specimen indicating a good impregnation. In this experiment, the fiber volume fractions of the srPET composites were approximately $46 \%$.

\subsection{Mechanical tests}

In this study, a universal testing machine (AG$100 \mathrm{kNX}$, Shimadzu, Japan) was used to perform the tensile and three-point bending flexural tests at room temperature according to ASTM D3039 and D790, respectively. Tensile specimens cut from the prepared srPET samples were $250 \times 25 \times 2 \mathrm{~mm}^{3}$ in normal dimension and were clamped over an area of $50 \times 25 \mathrm{~mm}^{2}$ at each end leaving a gauge length of $150 \mathrm{~mm}$. Aluminum tabs were glued onto the ends

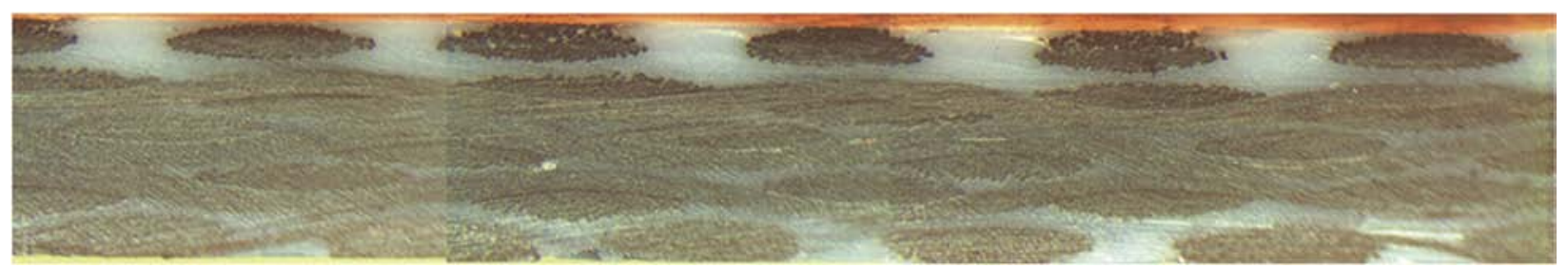

Figure 3. Light microscopic image of a srPET sample's cross section showing a good impregnation $\left(T_{\mathrm{c}} 225^{\circ} \mathrm{C} / \mathrm{t}_{\mathrm{h}} 6.5 \mathrm{~min}\right)$ 
of specimen to aid gripping areas. The grip pressure was hydraulically controlled. The testing crosshead speeds were $5 \mathrm{~mm} / \mathrm{min}$ for the tensile test. The axial displacement was measured by the machine according to the movement of the crosshead. Threepoint bending test was conducted to evaluate the flexural properties of the srPET composites. Specimens in $100 \mathrm{~mm}$ long and $12 \mathrm{~mm}$ wide by $2 \mathrm{~mm}$ thick were cut from the srPET composite plates. A span length of $64 \mathrm{~mm}$ assured a span-to-depth ratio of 32 , and a crosshead speed of $3.4 \mathrm{~mm} / \mathrm{min}$ was adopted. The Izod impact test was performed at room temperature according to ASTM D256 on a pendulum impact tester (CPI, Atlas electric devices, USA) at impact energy of 5.4 J. The impact velocity used was $3.4 \mathrm{~m} / \mathrm{sec}$. The dimensions for the Izod impact specimen were $63.5 \times 12.7 \times 2 \mathrm{~mm}^{3}$, and were provided with a $2.7 \pm 0.2 \mathrm{~mm}$ deep notch. The notches in the samples were opened by using a notch opener (QC-640, Cometech testing machines, Taiwan), and were all with a notch tip radius of $0.25 \mathrm{~mm}$. All the mechanical properties reported represent the average value of five readings at least.

\section{Results and discussion}

\subsection{Effects of consolidation temperature, $T_{c}$}

Figure 4 shows the typical tensile stress-strain curves of the srPET composites at different consolidation temperatures with an identical holding time (6.5 min). The results revealed a brittle type direct failure curve for the pure polyester resin. However, the curves for all the srPET composites displayed significant yielding and post yield strain hardening, indicating the reinforcing effect and structural

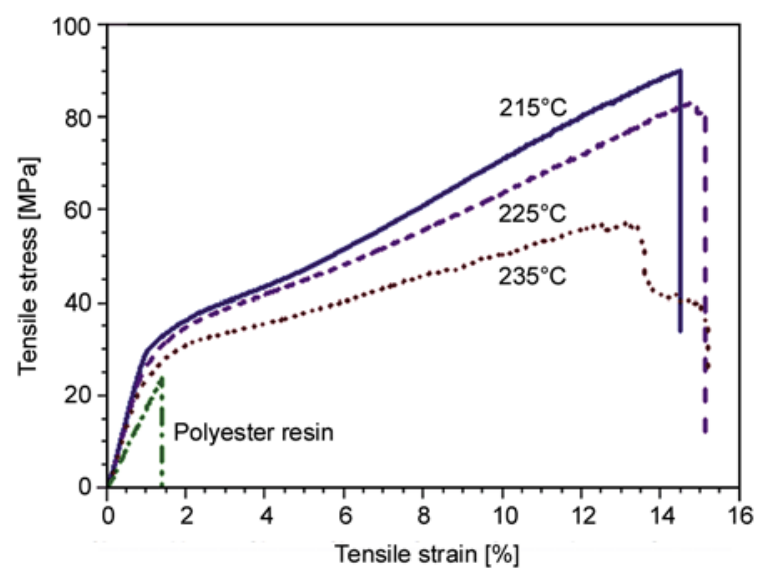

Figure 4. Typical tensile stress-strain curves of the srPET composites at different consolidation temperatures, $T_{\mathrm{c}}\left(t_{\mathrm{h}}: 6.5 \mathrm{~min}\right)$ homogeneity for the srPET composites. The $235^{\circ} \mathrm{C}$ sample demonstrates a severely vibrating curve before the final catastrophic fracture. However, a relatively smooth curve was observed in the sample of $215^{\circ} \mathrm{C}$. Please notice that the tensile elongation for the srPET samples of 215 and $225^{\circ} \mathrm{C}$ is approximately $14 \%$ which is the same as that of the PET yarn. That means the PET yarn bears most of external loads and exhibits its reinforcing effect with the aid of the protecting polyester matrix. However, premature fiber breakages were found in the srPET samples of $235^{\circ} \mathrm{C}$. Due to the plain-woven interlaced structure, stress concentration occurred on the fiber bundles around the interlaced point and led to breakage of the fiber bundles. Two kinds of tensile damage exist: break-apart (Figure 5a) and split/ delamination (Figure 5b), were noticed for the 215 and $235^{\circ} \mathrm{C}$ srPET samples, respectively. The failure modes of $215^{\circ} \mathrm{C}$ sample are matrix fracture, shortrange delamination, and multifilament bundle breakage. As for the $235^{\circ} \mathrm{C}$ sample, many sub-critical failures occurred after the yield point and caused the repeated fluctuation in tensile stress. A close visual observation of the test specimens suggested that the matrix fracture and shear breakage of the multifilament bundle over the length of the specimen occurred during the failure process. When the bundle split or experienced breakage, the released fractured energy dissipated with large amounts of long-range delamination, resulting in stress vibration. The difference in tensile damages could be

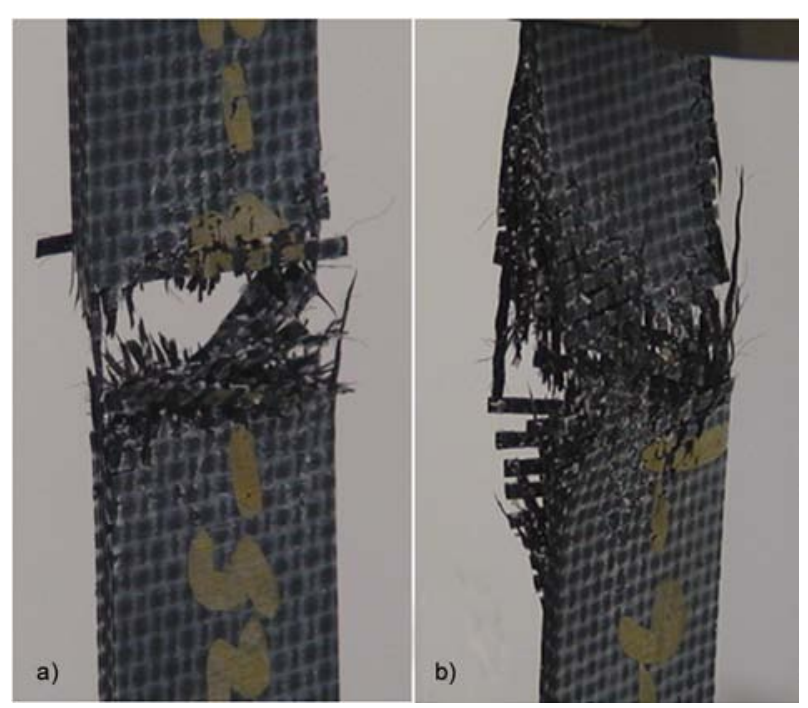

Figure 5. Typical tensile failure images for srPET composites. (a) break-apart damage for consolidation temperature, $T_{\mathrm{c}} 215^{\circ} \mathrm{C}$ srPET sample, (b) split/ delamination damage for $T_{\mathrm{c}} 235^{\circ} \mathrm{C}$ SPC sample 
attributed to the thermal degradation of the polyester matrix and poor interfacial adhesion at higher consolidation temperatures.

Please consider that the failure elongation for pure polyester resin is approximately $1.5 \%$, which is near the yielding elongation for the srPET composites. This is clear evidence demonstrating the reinforcing effect of the srPET composites. The slope between the yielding to failure point (called the post-yield modulus) represents the reinforcing efficiency of the srPET composites. The post-yield modulus decreased with increasing the $T_{\mathrm{c}}$ and resulted in tensile strength debasement. This post-yield modulus and strength debasement was due to the thermal degradation of the polyester matrix and the resulting poor interfacial adhesion [8]. Therefore, Table 1 summarizes the four tensile properties: Young's modulus, tensile strength, yield strength and postyield modulus. The srPET composites reveal a noteworthy improvement in mechanical properties compared to the polyester resin. All of the tensile properties of the srPET composites decrease when the $T_{\mathrm{c}}$ increases. The srPET composite consolidates at a low temperature of $215^{\circ} \mathrm{C}$, exhibits the highest modulus of $3.32 \mathrm{GPa}$, and strength: $95.5 \mathrm{MPa}$, with 76 and $366 \%$ enhancement, respectively, when compared to the polyester resin. When the $T_{\mathrm{c}}$ elevated from 215 to $235^{\circ} \mathrm{C}$, the modulus and yield strength decreased slightly from $3.32 \mathrm{GPa}$ and 30.5 $\mathrm{MPa}$ to $3.01 \mathrm{GPa}$ and $27.7 \mathrm{MPa}$, which relates to the loss of orientation of the reinforcing fibers and the degradation of the polyester matrix [35]. As for the tensile strength, it decreased from 90.9 to $60.9 \mathrm{MPa}$, which was due to the thermal degradation of the polyester resin and poor interfacial adhesion. This means that a higher $T_{\mathrm{c}}$ did not contribute to impregnation enhancement, but caused matrix thermal degradation and poor interfacial adhesion.

Table 2 summarizes the flexural and Izod impact properties of the srPET composites at different con-

Table 1. Tensile properties for the srPET composites produced at different consolidation temperatures

\begin{tabular}{|l|c|c|c|c|}
\hline $\mathbf{T}_{\mathbf{c}}\left[{ }^{\circ} \mathbf{C}\right] / \mathbf{t}_{\mathbf{h}}[\mathbf{m i n}]$ & $\begin{array}{c}\text { Tensile } \\
\text { modulus } \\
{[\mathbf{G P a}]}\end{array}$ & $\begin{array}{c}\text { Tensile } \\
\text { strength } \\
{[\mathbf{M P a}]}\end{array}$ & $\begin{array}{c}\text { Yield } \\
\text { strength } \\
{[\mathbf{M P a}]}\end{array}$ & $\begin{array}{c}\text { Post-yield } \\
\text { modulus } \\
{[\mathbf{G P a}]}\end{array}$ \\
\hline $\mathrm{PET}^{*}$ & $1.87 \pm 0.06$ & $20.5 \pm 7.1$ & $\mathrm{NA}$ & $\mathrm{NA}$ \\
\hline $215 / 6.5$ & $3.32 \pm 0.06$ & $90.9 \pm 0.6$ & $30.5 \pm 0.6$ & $0.49 \pm 0.02$ \\
\hline $225 / 6.5$ & $3.23 \pm 0.03$ & $85.0 \pm 3.2$ & $28.8 \pm 2.8$ & $0.47 \pm 0.03$ \\
\hline $235 / 6.5$ & $3.01 \pm 0.13$ & $60.9 \pm 3.2$ & $27.7 \pm 2.3$ & $0.32 \pm 0.02$ \\
\hline
\end{tabular}

${ }^{*}$ Pure polyester samples prepared at $T_{\mathrm{c}}: 200^{\circ} \mathrm{C} / \mathrm{t}_{\mathrm{h}}: 3 \mathrm{~min}$ solidation temperatures with an identical holding time $(6.5 \mathrm{~min})$. Similarly to the tensile results, the flexural modulus, and impact energy of the srPET composites decrease when the $T_{\mathrm{c}}$ increases. The flexural and impact properties of the srPET composites revealed a large improvement compared to those of the polyester resin. The pure polyester sample fractured at 5\% flexural deflection, however, the srPET composites did not collapse within the crosshead limit. This reveals the prevention ability from crack propagation by the reinforcing woven fabric. This study did not find any visible failures in the bent srPET samples, which demonstrates its highly tough character. The srPET composite consolidates at a low temperature of $215^{\circ} \mathrm{C}$ and exhibits the highest flexural modulus: $3.81 \mathrm{GPa}$, and strength: 66.0 MPa, with 90 and $21 \%$ enhancement, respectively, when compared to the polyester resin. When the $T_{\mathrm{c}}$ elevates above $225^{\circ} \mathrm{C}$, the flexural modulus slightly decreases to $3.49 \sim 3.63 \mathrm{GPa}$, which is still much higher than that of polyester matrix with value of $2.10 \mathrm{GPa}$. However, there is no difference in flexural strength between the srPET composites and the pure matrix material. This indicates a poor interfacial adhesion between the reinforcing fabric and matrix.

Table 2 shows the resulting notched Izod impact energy of the srPET composites, which exhibited extremely high impact absorption properties, when compared to the pure polyester resin. Unlike the impact fracture that occurred in the pure polyester sample, the srPET composites failed in a tough manner with tensile and compressive failures, and did not break apart (Figure 6). The figure revealed the prevention ability of the crack propagation by the reinforcing woven fabric. When the impactor encountered the srPET specimen, the fiber-bundle breakage occurred around the notched side first, while compressive force amassed around the other

Table 2. Flexural and impact properties for the srPET composites produced at different consolidation temperatures

\begin{tabular}{|l|c|c|c|}
\hline $\mathbf{T}_{\mathbf{c}}\left[{ }^{\circ} \mathbf{C}\right] / \mathbf{t}_{\mathbf{h}}[\mathbf{m i n}]$ & $\begin{array}{c}\text { Flexural } \\
\text { modulus } \\
{[\mathbf{G P a}]}\end{array}$ & $\begin{array}{c}\text { Flexural } \\
\text { strength } \\
{[\mathbf{M P a}]}\end{array}$ & $\begin{array}{c}\text { Impact } \\
\text { energy } \\
{[\mathbf{J} / \mathbf{m}]}\end{array}$ \\
\hline PET $^{*}$ & $2.01 \pm 0.10$ & $54.6 \pm 2.7$ & $13.5 \pm 1.6$ \\
\hline $215 / 6.5$ & $3.81 \pm 0.07$ & $66.0 \pm 0.6$ & $715.6 \pm 82.0$ \\
\hline $225 / 6.5$ & $3.63 \pm 0.08$ & $55.8 \pm 0.8$ & $685.9 \pm 9.1$ \\
\hline $235 / 6.5$ & $3.49 \pm 0.04$ & $55.1 \pm 0.2$ & $493.3 \pm 78.4$ \\
\hline
\end{tabular}

*Pure polyester samples prepared at $T_{\mathrm{c}}: 200^{\circ} \mathrm{C} / \mathrm{t}_{\mathrm{h}}: 3 \mathrm{~min}$ 


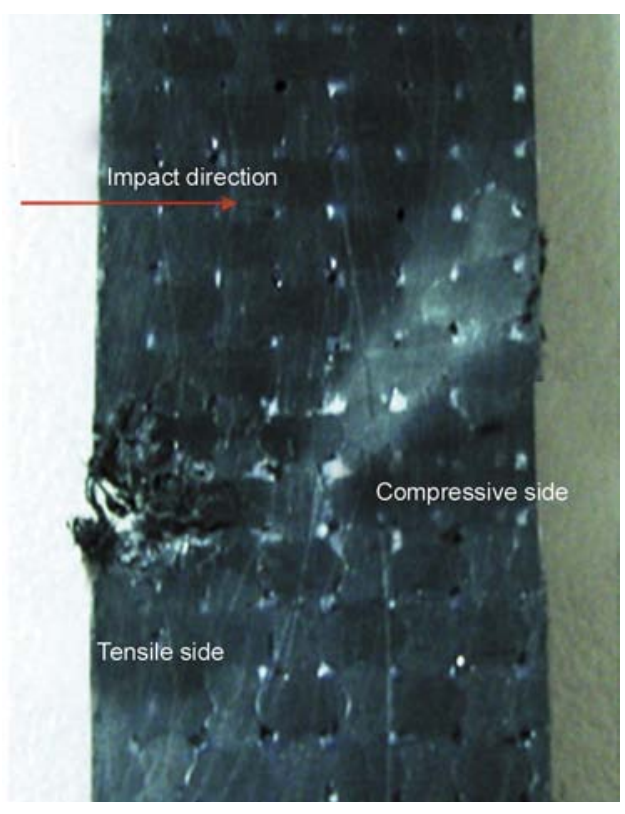

Figure 6. Photograph of the Izod impact tested srPET specimen

side of specimen. Due to the laminated nature and integrity of the woven fabric architecture, this study observed fiber bundle breakage near the notch area followed by extensive delamination along the interlaminate interface. Figure 7 shows a typical $45^{\circ}$ compressive shearing failure occurring on the compressive side of the srPET samples that accompany the fiber breakage (kink and buckle), the matrix crush, and delaminations. The srPET composite consolidates at $215^{\circ} \mathrm{C}$, elevates the impact energy from the value of $13.5 \mathrm{~J} / \mathrm{m}$ for pure polyester resin to $715.6 \mathrm{~J} / \mathrm{m}$, with a 53 -fold enhancement. Due to the loss orientation of reinforcing fibers and the degradation of the polyester matrix at high Tc, the impact energy decreased up to $31 \%$ when Tc increased. However, the impact energy for the $235^{\circ} \mathrm{C}$ sample is $493.3 \mathrm{~J} / \mathrm{m}$, which still has a 37 -fold enhancement to the pure polyester resin.

\subsection{Effects of holding time, $t_{h}$}

Figure 8 shows the typical tensile stress-strain curves of the srPET composites at different holding times $(3,6.5$, and $10 \mathrm{~min})$ with $T_{\mathrm{c}}$ at $225^{\circ} \mathrm{C}$. The break-apart damage (Figure 5a) was found for the 3 min sample, while the split/delamination damage as shown in Figure $5 \mathrm{~b}$ was noticed for long holding time srPET samples: 6.5 and $10 \mathrm{~min}$. It is noteworthy to check the effect of holding time on the initial modulus, post-yield modulus, and tensile strain. Little deviation of the initial modulus and postyield modulus with holding time was evidence for samples consolidated at $225^{\circ} \mathrm{C}$ with comparable fiber orientation and interfacial adhesion. The tensile strain decreased with the increasing $t_{\mathrm{h}}$. This premature failure for long holding time samples was attributed to the degradation and embrittlement of the polyester matrix $[9,19,25]$. Tensile properties: Young's modulus, tensile strength, yield strength and post-yield modulus were thus determined and summarized in Table 3 . When the $t_{\mathrm{h}}$ prolonged from 3 to $10 \mathrm{~min}$, the tensile strength decreased slightly

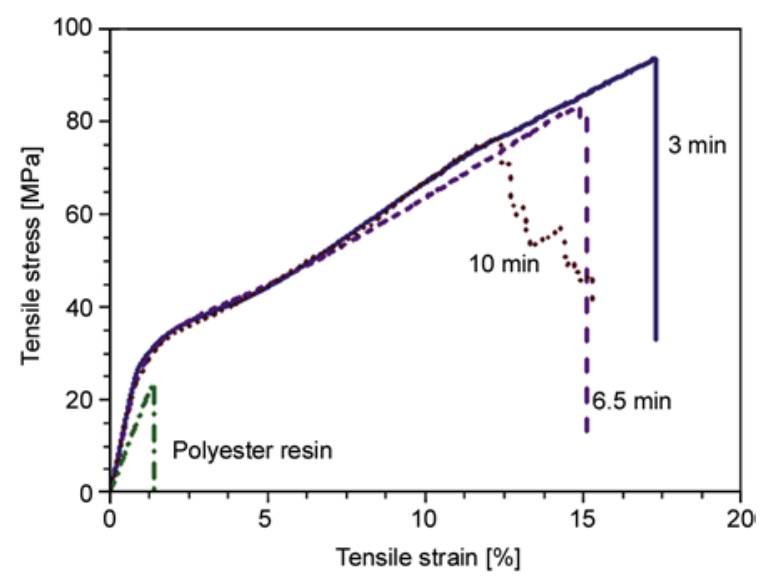

Figure 8. Typical tensile stress-strain curves of the srPET composites at different holding times, $t_{\mathrm{h}}\left(T_{\mathrm{c}}\right.$ : $225^{\circ} \mathrm{C}$ )

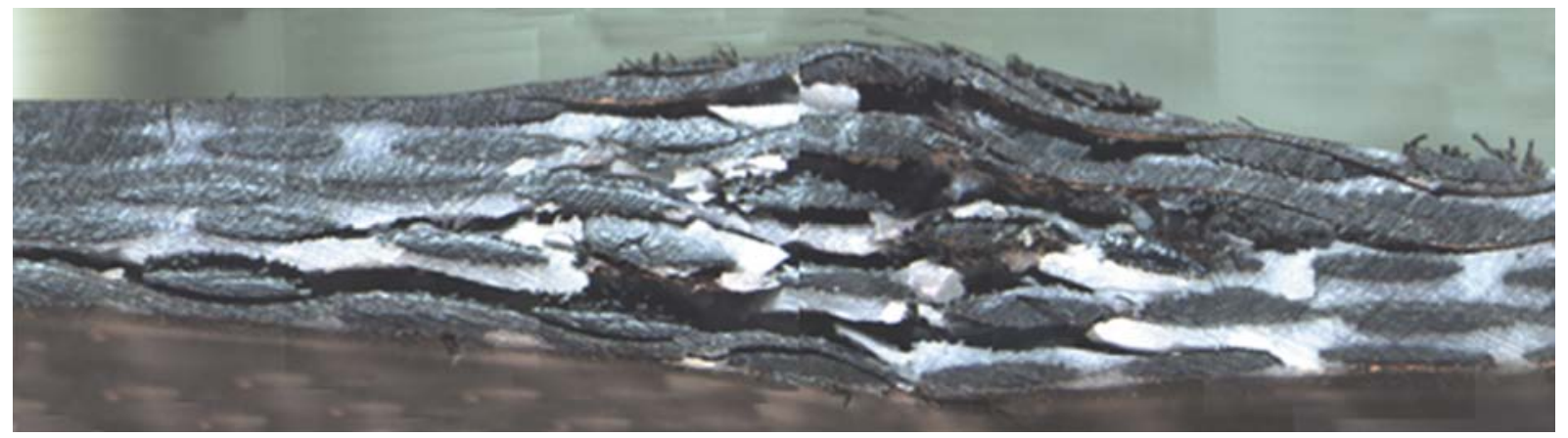

Figure 7. A typical $45^{\circ}$ compressive shearing failure occurs in the compressive side of srPET composites accompany with fiber breakage, matrix crush, and delaminations 
Table 3. Tensile properties for the srPET composites produced at different holding times

\begin{tabular}{|l|c|c|c|c|}
\hline $\mathbf{T}_{\mathbf{c}}\left[{ }^{\circ} \mathbf{C}\right] / \mathbf{t}_{\mathbf{h}}[\mathbf{m i n}]$ & $\begin{array}{c}\text { Tensile } \\
\text { modulus } \\
{[\mathbf{G P a}]}\end{array}$ & $\begin{array}{c}\text { Tensile } \\
\text { strength } \\
{[\mathbf{M P a}]}\end{array}$ & $\begin{array}{c}\text { Yield } \\
\text { strength } \\
{[\mathbf{M P a}]}\end{array}$ & $\begin{array}{c}\text { Post-yield } \\
\text { modulus } \\
{[\mathbf{G P a}]}\end{array}$ \\
\hline $\mathrm{PET}^{*}$ & $1.87 \pm 0.06$ & $20.5 \pm 7.1$ & $\mathrm{NA}$ & $\mathrm{NA}$ \\
\hline $225 / 3$ & $3.30 \pm 0.08$ & $95.5 \pm 2.7$ & $31.1 \pm 1.5$ & $0.42 \pm 0.04$ \\
\hline $225 / 6.5$ & $3.23 \pm 0.03$ & $85.0 \pm 3.2$ & $28.8 \pm 2.8$ & $0.47 \pm 0.03$ \\
\hline $225 / 10$ & $3.24 \pm 0.10$ & $77.4 \pm 2.4$ & $29.0 \pm 2.8$ & $0.47 \pm 0.02$ \\
\hline $215 / 3$ & $3.29 \pm 0.07$ & $119.1 \pm 5.6$ & $31.3 \pm 1.8$ & $0.47 \pm 0.01$ \\
\hline
\end{tabular}

*Pure polyester samples prepared at $T_{\mathrm{c}}: 200^{\circ} \mathrm{C} / t_{\mathrm{h}}: 3 \mathrm{~min}$

from 95.5 to $77.7 \mathrm{MPa}$, which relates to the degradation and embrittlement of the polyester matrix. This study shows that the best tensile strength had a value of up to $95.5 \mathrm{MPa}$ when sampled at a $3 \mathrm{~min}$ holding time, which is a 4.7-fold enhancement over that of the pure polyester resin.

Table 4 summarizes the flexural and Izod impact properties of the srPET composites at different holding times with $T_{\mathrm{c}}$ at $225^{\circ} \mathrm{C}$. A slight influence of the flexural properties with holding time was evidenced for samples consolidated at $225^{\circ} \mathrm{C}$ with comparable interfacial adhesion. The srPET sample with 3 min holding time, exhibited the highest flexural properties. The srPET sample with a holding time longer than $6.5 \mathrm{~min}$ at $225^{\circ} \mathrm{C}$, exhibited the same flexural strength as pure matrix material. This caused a premature failure of the interphase due to the degradation and embrittlement of the polyester matrix.

The impact energy of the srPET composites decreased when the holding time increased, from 811.3 to $422.4 \mathrm{~J} / \mathrm{m}$ at $T_{\mathrm{c}} 225$ : clear evidence that degradation and embrittlement of the polyester matrix took place at $T_{\mathrm{c}}$ above $225^{\circ} \mathrm{C}$. The rapid process $\left(t_{\mathrm{h}}: 3 \mathrm{~min}\right)$ for srPET composite consolidated at $225^{\circ} \mathrm{C}$ elevated the impact energy from value of 13.5 (polyester matrix) to $811.3 \mathrm{~J} / \mathrm{m}$, with a 60-fold enhancement.

Table 4. Flexural and impact properties for the srPET composites produced at different holding times

\begin{tabular}{|l|c|c|c|}
\hline $\mathbf{T}_{\mathbf{c}}\left[{ }^{\circ} \mathbf{C}\right] / \mathbf{t}_{\mathbf{h}}[\mathbf{m i n}]$ & $\begin{array}{c}\text { Flexural } \\
\text { modulus } \\
{[\mathbf{G P a}]}\end{array}$ & $\begin{array}{c}\text { Flexural } \\
\text { strength } \\
{[\mathbf{M P a}]}\end{array}$ & $\begin{array}{c}\text { Impact } \\
\text { energy } \\
{[\mathbf{J} / \mathbf{m}]}\end{array}$ \\
\hline PET $^{*}$ & $2.01 \pm 0.10$ & $54.6 \pm 2.7$ & $13.5 \pm 1.6$ \\
\hline $225 / 3$ & $3.65 \pm 0.19$ & $61.0 \pm 0.4$ & $811.3 \pm 59.6$ \\
\hline $225 / 6.5$ & $3.63 \pm 0.08$ & $55.8 \pm 0.8$ & $685.9 \pm 9.1$ \\
\hline $225 / 10$ & $3.53 \pm 0.08$ & $56.6 \pm 0.8$ & $422.4 \pm 39.4$ \\
\hline $215 / 3$ & $4.21 \pm 0.20$ & $81.0 \pm 6.8$ & $854.0 \pm 68.2$ \\
\hline
\end{tabular}

${ }^{*}$ Pure polyester samples prepared at $T_{\mathrm{c}}: 200^{\circ} \mathrm{C} / \mathrm{t}_{\mathrm{h}}: 3 \mathrm{~min}$
To summarize the srPET composites study, the processing conditions proved to influence the mechanical properties of the srPET composites significantly, such as with consolidation temperature and holding time. This is due to the degradation and embrittlement of the polyester matrix. Optimal process conditions including a consolidation temperature of $T_{\mathrm{c}}$ : $215^{\circ} \mathrm{C}$ and a holding time of $t_{\mathrm{h}}: 3 \mathrm{~min}$, were thus conceived. As revealed in Table 3, its tensile strength increases further from 95.5 to $119.1 \mathrm{MPa}$. In addition, the flexural modulus and strength improve further to $4.21 \mathrm{GPa}$ and $81.0 \mathrm{MPa}$, respectively (Table 4). The impact energy for the optimal processed srPET sample elevated from value of 13.5 (polyester resin) to $854.0 \mathrm{~J} / \mathrm{m}$, with a 63 -fold enhancement.

\section{Conclusions}

In this study srPET composites were prepared by utilizing the modified film stacking technique to laminate a thin polyester film and woven PET fabrics. Experimental results showed that the srPET composites display significant improvement in their tensile, flexural, and impact properties when compared to the non-reinforced polyester matrix. Due to the degradation and embrittlement of the polyester matrix, the mechanical properties strongly affected the consolidation temperature and holding time. The srPET composites with a low consolidation temperature at $215^{\circ} \mathrm{C}$ and a short holding time of 3 min displayed the best mechanical properties. The tensile strength, flexural modulus and strength were largely improved to $119.1 \mathrm{MPa}, 4.21 \mathrm{GPa}$ and 81.0 MPa. The absorbed impact energy of the best srPET composites was $854.0 \mathrm{~J} / \mathrm{m}$, which is 63 times that of pure polyester resin.

\section{Acknowledgements}

Part of this work is financially supported from the National Science Council of Taiwan, ROC, under contract number NSC 99-2632-E-035-001 -MY3.

\section{References}

[1] Pegoretti A.: Trends in composite materials: The challenge of single-polymer composites. Express Polymer Letters, 1, 710 (2007).

DOI: 10.3144/expresspolymlett.2007.97 
[2] Matabola K. P., DeVries A. R., Moolman F. S., Luyt A. S.: Single polymer composites: A review. Journal of Materials Science, 44, 6213-6222 (2009).

DOI: $10.1007 / \mathrm{s} 10853-009-3792-1$

[3] Kmetty Á., Bárány T., Karger-Kocsis J.: Self-reinforced polymeric materials: A review. Progress in Polymer Science, 35, 1288-1310 (2010).

DOI: 10.1016/j.progpolymsci.2010.07.002

[4] Fakirov S., Duhovic M., Maitrot P., Bhattacharyya D.: From PET nanofibrils to nanofibrillar single-polymer composites. Macromolecular Materials and Engineering, 295, 515-518 (2010). DOI: $10.1002 /$ mame.200900387

[5] Morgan L. M., Weager B. M., Hare C. M., Bishop G. R., Smith G. M.: Self reinforced polymer composites: Coming of age. in 'Proceeding of the $17^{\text {th }}$ International Conference on Composite Materials, Edinburgh, UK' ID12:15 (2009).

[6] Capiati N. J., Porter R. S.: The concept of one polymer composites modelled with high density polyethylene. Journal of Materials Science, 10, 1671-1677 (1975). DOI: $10.1007 / \mathrm{BF} 00554928$

[7] Hine P. J., Ward I. M., Maaty M. I. A., Olley R. H., Basset D. C.: The hot compaction of 2-dimensional woven melt spun high modulus polyethylene fibers. Journal of Materials Science, 35, 5091-5099 (2000). DOI: $10.1023 / \mathrm{A}: 1004835816735$

[8] Hine P. J., Ward I. M., Jordan N. D., Olley R. H., Basset D. C.: The hot compaction behaviour of woven oriented polypropylene fibres and tapes. I. Mechanical properties. Polymer, 44, 1117-1131 (2003). DOI: $10.1016 / \mathrm{S} 0032-3861(02) 00809-1$

[9] Hine P. J., Ward I. M.: Hot compaction of woven poly(ethylene terephthalate) multifilaments. Journal of Applied Polymer Science, 91, 2223-2233 (2004). DOI: 10.1002/app.13343

[10] Ward I. M., Hine P. J.: The science and technology of hot compaction. Polymer, 45, 1413-1427 (2004). DOI: $10.1016 /$ j.polymer.2003.11.050

[11] Hine P. J., Olley R. H., Ward I. M.: The use of interleaved films for optimising the production and properties of hot compacted, self reinforced polymer composites. Composites Science and Technology, 68, 1413-1421 (2008).

DOI: $10.1016 /$ j.compscitech.2007.11.003

[12] Alcock B., Cabrera N. O., Barkoula N-M., Loos J., Peijs T.: The mechanical properties of unidirectional all-polypropylene composites. Composites Part A: Applied Science and Manufacturing, 37, 716-726 (2006).

DOI: 10.1016/j.compositesa.2005.07.002

[13] Khondker O. A., Yang X., Usui N., Hamada H.: Mechanical properties of textile-inserted PP/PP knitted composites using inject-compression molding. Composites Part A: Applied Science and Manufacturing, 37, 2285-2299 (2006).

DOI: $10.1016 /$ j.compositesa.2005.12.032
[14] Abraham T., Banik K., Karger-Kocsis J.: All-PP composites $\left(\right.$ Pure $^{\circledR}$ ) with unidirectional and cross-ply layups: Dynamic mechanical thermal analysis. Express Polymer Letters, 1, 519-526 (2007).

DOI: $10.3144 /$ expresspolymlett.2007.74

[15] Bárány T., Karger-Kocsis J., Czigány T.: Development and characterization of self-reinforced poly(propylene) composites: Carded mat reinforcement. Polymers for Advanced Technologies, 17, 818-824 (2006). DOI: $10.1002 /$ pat.813

[16] Izer A., Bárány T.: Effect of consolidation on the flexural creep behaviour of all-polypropylene composite. Express Polymer Letters, 4, 210-216 (2010). DOI: $10.3144 /$ expresspolymlett.2010.27

[17] Alcock B., Cabrera N. O., Barkoula N-M., Loos J., Peijs T.: The mechanical properties of unidirectional all-polypropylene composites. Composites Part A: Applied Science and Manufacturing, 37, 716-726 (2006).

DOI: 10.1016/j.compositesa.2005.07.002

[18] Rojanapitayakorn P., Mather P. T., Goldberg A. J., Weiss R. A.: Optical transparent self-reinforced poly (ethylene terephthalate) composites: Molecular orientation and mechanical properties. Polymer, 46, 761773 (2005).

DOI: 10.1016/j.polymer.2004.11.032

[19] Yao D., Li R., Nagarajan P.: Single-polymer composites based on slowly crystallizing polymers. Polymer Engineering and Science, 46, 1223-1230 (2006). DOI: 10.1002/pen.20583

[20] Wright D. D., Lautenschlager E. P., Gilbert J. L.: Bending and fracture toughness of woven self-reinforced composite poly(methyl methacrylate). Journal of Biomedical Materials Research, 36, 441-453 (1997). DOI: 10.1002/(SICI)1097-4636(19970915)36:4<441:: AID-JBM2>3.0.CO;2-E

[21] Pegoretti A., Zanolli A., Migliaresi C.: Flexural and interlaminar mechanical properties of unidirectional liquid crystalline single-polymer composites. Composites Science and Technology, 66, 1953-1962 (2006). DOI: 10.1016/j.compscitech.2006.01.015

[22] Pegoretti A., Zanolli A., Migliaresi C.: Preparation and tensile mechanical properties of unidirectional liquid crystalline single-polymer composites. Composites Science and Technology, 66, 1970-1979 (2006). DOI: 10.1016/j.compscitech.2006.01.012

[23] Li R., Yao D.: Preparation of single poly(lactic acid) composites. Journal of Applied Polymer Science, 107, 2909-2916 (2008).

DOI: 10.1002/app.27406

[24] Bhattacharyya D., Maitrot P., Fakirov S.: Polyamide 6 single polymer composites. Express Polymer Letters, 3, 525-532 (2009).

DOI: 10.3144 /expresspolymlett.2009.65 
[25] Khondker O. A., Fukui T., Inoda M., Nakai A., Hamada H.: Fabrication and mechanical properties of aramid/nylon plain knitted composites. Composites Part A: Applied Science and Manufacturing, 35, 11951205 (2004).

DOI: $10.1016 /$ j.compositesa.2004.03.004

[26] Hine P. J., Ward I. M.: Hot compaction of woven nylon 6,6 multifilaments. Journal of Applied Polymer Science, 101, 991-997 (2006).

DOI: $10.1002 / a p p .22771$

[27] Teishev A., Incardona S., Migliaresi C., Marom G.: Polyethylene fibers-polyethylene matrix composites: Preparation and physical properties. Journal of Applied Polymer Science, 50, 503-512 (1993).

DOI: 10.1002/app.1993.070500314

[28] Marais C., Feillard P.: Manufacturing and mechanical characterization of unidirectional polyethylene-fibre/ polyethylene-matrix composites. Composites Science and Technology, 45, 247-255 (1992).

DOI: 10.1016/0266-3538(92)90086-I

[29] Houshyar S., Shanks R. A., Hodzic A.: The effect of fiber concentration on mechanical and thermal properties of fiber-reinforced polypropylene composites. Journal of Applied Polymer Science, 96, 2260-2272 (2005).

DOI: 10.1002/app.20874

[30] Houshyar S., Shanks R. A.: Tensile properties and creep response of polypropylene fibre composites with variation of fibre diameter. Polymer International, 53, 1752-1759 (2004).

DOI: $10.1002 /$ pi.1569
[31] Houshyar S., Shanks R. A., Hodzic A.: Influence of different woven geometry in poly(propylene) woven composites. Macromolecular Materials and Engineering, 290, 45-52 (2005).

DOI: $10.1002 /$ mame. 200400158

[32] Bárány T., Izer A., Karger-Kocsis J.: Impact resistance of all-polypropylene composites composed of alpha and beta modifications. Polymer Testing, 28, 176-182 (2009).

DOI: $10.1016 /$ j.polymertesting.2008.11.011

[33] Alcock B., Cabrera N. O., Barkoula N-M., Spoelstra A. B., Loos J., Peijs T.: The mechanical properties of woven tape all-polypropylene composites. Composites Part A: Applied Science and Manufacturing, 38, 147161 (2007).

DOI: 10.1016/j.compositesa.2006.01.003

[34] Bárány T., Izer A., Czigány T.: On consolidation of self-reinforced polypropylene composites. Plastics, Rubber and Composites, 35, 375-379 (2006). DOI: $10.1179 / 174328906 X 128234$

[35] Alcock B., Cabrera N. O., Barkoula N. M., Peijs T.: The effect of processing conditions on the mechanical properties and thermal stability of highly oriented PP tapes. European Polymer Journal, 45, 2878-2894 (2009).

DOI: 10.1016/j.eurpolymj.2009.06.025 